\title{
THE EFFECT OF MICRON SIZED WOOD FIBERS IN WOOD PLASTIC COMPOSITES
}

\author{
Lance W. Gallagher ${ }^{1,2}$, Armando G. McDonald ${ }^{1 \star}$
}

\begin{abstract}
The popularity and demand for wood plastic composites (WPC) has focused research on fiber properties associated with performance. In this study, maple wood fibers (WF) were ball milled and classified into discrete size fractions. Fiber analyses showed only three distinct WF size classes (80-100, 100-200 and $<200$ mesh). High density polyethylene (HDPE) based WPC were made from classified WF (10 to 50\%). The effect of WF size, loading, and maleated polyethylene (MAPE) coupling agent on WPC rheological behavior (torque rheometry and melt flow rate (MFR)) and flexural properties were examined. The WPC MFR decreased with wood loading, increased with a reduction in WF size. The modulus of rupture (MOR) was shown to increase with a reduction in WF size and increase with the addition of MAPE. The increase in MOR is likely due to an increase in the interfacial interaction between the polymer and WF. Modulus of elasticity (MOE) was shown to increase with an increase in wood loading and decrease with a decrease in WF size. The toughness of the WPC was shown to increase with a decrease in WF size and increase upon addition of MAPE.
\end{abstract}

Keywords: Flexural properties, HDPE, rheometry, wood fiber, wood plastic composites,

\section{INTRODUCTION}

A growing trend in decking is the use of composite decking, which boasts several advantages over its natural competitor, wood. Composite decking is made up of two main ingredients, WF and a thermoplastic matrix (such as HDPE, polypropylene, or polyvinylchloride), as well as additives that aid processing of the product and add color, dispersants and coupling agents, ultra-violet/light stabilizers, and biocides (Clemons 2002). The makeup of these WPC allows decking to be highly durable and have lower maintenance associated with it (Morrell et al. 2006, Fabiyi et al. 2008, 2010, 2011).

An extensive body of research has been conducted on the effect that WF size has on WPC properties (Liew et al. 2000, Stark and Berger 1997ab, Stark and Rowlands 2003, Zaini et al. 1995, Maiti and Hassan 1989, Li and Wolcott 2005, Marcovich et al. 2004, Lee et al. 2001). Several studies have specifically examined the effect of WF size on mechanical properties (Liew et al. 2000, Stark and Berger 1997ab, Stark and Rowlands 2003, Zaini et al. 1995, Lee et al. 2001). The results from these studies show that aspect ratio has the largest effect on WPC mechanical performance (Stark and Rowlands 2003). WF, which is currently incorporated into commercial WPC formulations, range in size from 10 to 80 mesh (1700 to $180 \mu \mathrm{m})$ (Clemons 2002). A survey of literature suggests that the smallest WF size investigated is no smaller than 235 mesh or $74 \mu \mathrm{m}$ (Stark and Rowlands 2003). As particle size of reinforcing agents decreases from macro- to micro- to nano-size in composite materials, dramatic enhancements in properties such as mechanical and barrier properties, flame retardency, and electrical conductivity increase (LeBaron 1999). The enhanced composites performance is due to optimized interfacial interaction between the matrix and filler particles and is due to the large surface area of the particles, which facilitate stress transfer to the reinforcing phase (Lim and Park 2001).

\footnotetext{
${ }^{1}$ Renewable Materials Program, Department of Forest, Rangeland and Fire Sciences, University of Idaho, Moscow, ID 83844-1132, USA ${ }^{2}$ Georgia-Pacific Chemicals, Albany, OR 97321, USA

^Corresponding author: armandm@uidaho.edu

Received: 31.10.2012. Accepted: 23.03.2013
} 
The majority of research conducted on WF size has focused on the effects of mechanical properties. However, little is understood on the effect of WF size on processability, such as rheological characteristics and a limited number of articles have investigated before 2000 (Maiti and Hassan 1989). Shenoy (1999) provides an extensive review that examines the rheology of fillers in polymer melts. Three different filler types (spheres, platelets, and fibers) were identified and discussed in relation to their polymer melt steady shear viscosity. Spherical fillers (glass beads) showed the lowest effect on increasing plastic melt viscosity followed by platelet fillers (micas and calcium carbonate), and finally by fibrous fillers (glass fibers), which showed the highest viscosity. In terms of filler concentration, the inter-particle interactions increase slightly as concentration increases at lower filler loadings; however, at higher filler content the inter-particle interactions increase strongly. The point at which these inter-particle interactions become strong depends on the size and shape of the particle. For particles with large aspect ratios, interaction between particles takes place at low loadings, while particles with a spherical shape do not interact until about $20 \%$. However, melt viscosity increases concurrently with increases in filler concentration (Shenoy 1999). Similar trends in terms of increased viscosity with increased aspect ratio or increased concentrations were also highlighted in the literature (Dae Han 1974, George et al. 1996, Guo et al. 2005, Dong et al. 1992).

Li and Wolcott $(2004,2005)$ examined the effect of WF species, size, and content (30-70\%) using capillary rheometry. Their results have showed that WF content has a major positive effect in shear and extensional properties of the WPC melt. This phenomenon showed a larger effect on properties than did fiber size or species. It was also shown that MAPE acts as an internal lubricant at high WF loadings (60-70\%) in both shear and extensional flow. On the other hand, it was found that there was a significant increase in shear and extensional flow at lower WF loadings (30-40\%) with the addition of MAPE (Li and Wolcott 2004, 2005). Marcovich et al. (2004) observed similar trends using dynamic rheological analysis to investigate the influence of WF in a PP melt. In addition, the WPC melt complex viscosity was shown to increase with an increase in wood content.

The aim of this study was to examine the effect of micron sized WF in WPC and the manner in which it affects processing and properties. Properties of formulations were evaluated utilizing torque rheometry, melt flow indexer, thermal analysis and flexural properties in order to investigate the effect of wood loading, WF size, and MAPE coupling agent.

\section{MATERIALS AND METHODS}

\section{Materials}

Commercial maple WF ( 80 mesh, American Wood Fibers) was used and sieve analysis was conducted on oven dried (OD) fiber (50 g) using a Soil Test shaker (Model CL-300B) with standard test sieves (80, 100, 200, 300, 400 mesh and pan) for $10 \mathrm{~min}$ (Dalsgaard et al. 1991). A fractionated 100 mesh WF fraction was obtained by screening (80-100 mesh fraction).

Micrometer-sized WFs were obtained after ball milling $(80 \mathrm{rpm})$ in a $4 \mathrm{~L}$ porcelain jar and porcelain balls for 7 days. The ball milled material was then fractionated into 80, 100, 200, 300 and 400 mesh and pan fractions.

\section{Fiber Analysis}

Three methods were used to measure fiber size: (i) sieve analysis (described above), (ii) light microscopy, and (iii) light scattering by single-particle optical sensing.

WF size was characterized by light scattering single particle optical sensing (Particle Sizing Systems, Inc. Model 770 AccuSizer). Briefly, WF $(50 \mathrm{mg})$ was dispersed in water $(25 \mathrm{~mL})$ at $400 \mathrm{rpm}$ for $1 \mathrm{~h}$ and a $0.5 \mathrm{~mL}$ aliquot of suspension diluted 500 fold. For each sample, triplicate analyses were performed and for each specimen at least 10,000 fibers were measured. The mean length weighted fiber length was calculated from the raw data according to McDonald et al. (1997). 
Light microscopy was performed using an Olympus BX51 optical microscope in bright field mode and images captured using an Olympus DP70 digital camera. Images were analyzed using the Olympus MicrosuiteTM-SE software package. A drop of the dispersed WF was placed on a glass slide and a cover slip applied and $100 \mathrm{WF}$ were analyzed for length and width to determine aspect ratio.

Observations were made on the bulk density of the sifted material. A measuring cylinder of a known volume $(100 \mathrm{~mL})$ was weighed and tared. The cylinder was then filled to the level with wood fiber with no tapping and reweighed to determine bulk density.

\section{Compounding, torque rheometry and sample preparation}

Screened maple fiber and HDPE (Equistar Petrothene Type LB01000) were oven dried $\left(24 \mathrm{~h}\right.$ at $\left.104^{\circ} \mathrm{C}\right)$ prior to blending and compounding in a Haake Polylab mixer/torque rheometer with a $60 \mathrm{~mL}$ Roller rotor $600 \mathrm{mixing}$ head at a fill capacity of 70\% (Cheng et al. 2001). Blends ranged between 10 and $50 \%$ wood and 0 and $2 \%$ MAPE (Polybond 3029, Crompton) were compounded at $163^{\circ} \mathrm{C}$ at $35 \mathrm{rpm}$ for $5 \mathrm{~min}$ in duplicate under near identical conditions (Table 1). Steady state torque values between duplicates were $<0.4 \mathrm{Nm}$. The compounded material was molded into flexural specimens $(3.1 \times 9.1 \times 60 \mathrm{~mm} 3)$ using a Dynisco laboratory mixing molder. The WPC specimens were conditioned $\left(65 \% \mathrm{RH}\right.$ at $\left.22^{\circ} \mathrm{C}\right)$ for at least 7 days prior to testing.

Table 1. WPC Formulations associated with compounding. Formulations containing $2 \%$ MAPE have a reduction in the amount of HDPE in the formulation by $2 \%$.

\begin{tabular}{ccccc}
\hline $\begin{array}{c}\text { WF content } \\
(\%)\end{array}$ & $\begin{array}{c}\text { WPC density } \\
\left(\mathrm{g} / \mathrm{cm}^{3}\right)\end{array}$ & $\begin{array}{c}\text { Wood weight } \\
(\mathrm{g})\end{array}$ & $\begin{array}{c}\text { HDPE weight } \\
(\mathrm{g})\end{array}$ & $\begin{array}{c}\text { Total formulation } \\
\text { weight }(\mathrm{g})\end{array}$ \\
\hline 50 & 0.990 & 23.91 & 23.91 & 47.82 \\
40 & 0.924 & 17.85 & 26.78 & 44.93 \\
30 & 0.875 & 12.68 & 29.58 & 42.26 \\
20 & 0.832 & 8.04 & 32.15 & 40.19 \\
10 & 0.789 & 3.81 & 34.30 & 38.11 \\
0 & 0.746 & - & - & - \\
\hline
\end{tabular}

\section{Flexural testing}

Three point bending tests (flexural strength (or modulus of rupture (MOR)), modulus of elasticity (MOE), and energy at maximum flexure extension (EMFE)) were performed according to ASTM Standard D 790-07 (2008) with a crosshead speed of $1.31 \mathrm{~mm} \mathrm{~min}^{-1}$ on an Instron 5500R-1137 test machine using the BlueHill v2 software.

\section{Melt Flow Rate}

MFR of molten WPC (4.0 g, 4 replicates) was measured through a die $(8 \mathrm{~mm} \times 2.0955 \mathrm{~mm} \varnothing)$ at a temperature of $190^{\circ} \mathrm{C}$ and load of $10 \mathrm{~kg}$. ASTM D 1238-01el (2008) standard procedure was used to assess the MFR of material using CEAST Modular Melt Flow Indexer (Model 7024.000). Average MFR and viscosity values resulted from each test. 


\section{Thermal Analysis}

Differential scanning calorimetry (DSC) was performed on a Mettler Toledo's FP84HT DSC and analyzed using Mettler-Toledo FP99A software to determine the extent of HDPE crystallinity within the WPC samples $(5.5 \mathrm{mg}$, in duplicate). Temperature program: equilibrated at $70^{\circ} \mathrm{C}(2 \mathrm{~min})$ then ramped at $10^{\circ} \mathrm{C} \mathrm{min}^{-1}$ to $180^{\circ} \mathrm{C}(3 \mathrm{~min})$, then cooled at $-10^{\circ} \mathrm{C} \mathrm{min}^{-1}$ to $70^{\circ} \mathrm{C}(3 \mathrm{~min})$, and the temperature cycle repeated. Crystallinity was calculated based on HDPE content from the ratio of the melting enthalpy $\left(105-144^{\circ} \mathrm{C}\right)$ of the sample to the melting enthalpy of $100 \%$ crystalline HDPE (293 J g ${ }^{-1}$ ) (Wunderlich 1973).

\section{Statistical Analysis}

Statistical analysis was performed on data using a commercial statistical software package (SPSS v10). A variety of tests were performed to determine the effect that the three independent variables, wood fiber size, loading, and MAPE coupling agent, had on final properties. Means were compared to determine the significance of wood fiber size and loading on properties and t-tests were calculated to determine if the addition of MAPE was significant. Further statistical tests were performed to see the significance of each independent variable's main effect and interaction effects among variables. Analysis of variances tests and multiple regression analyses were conducted to determine the direction and magnitude of these effects.

\section{Wood Fiber Analysis}

\section{RESULTS AND DISCUSSION}

Sieve analysis was performed throughout the ball milling process and after seven days milling over $90 \%$ of the WF produced were $<200$ mesh. Table 2 shows the yields of the classified WF. The greatest yield of material after ball milling was the 200-300 fraction, which accounted for $50 \%$ of the total WF. The $300-400$ and $<400$ fractions each gave approximately $20 \%$ yield.

Table 2. Fiber analysis (average WF size and aspect ratio) of ball milled maple WF classified fractions.

\begin{tabular}{|c|c|c|c|c|c|c|}
\hline \multicolumn{3}{|c|}{ Sieve Analysis } & Particle & \multicolumn{3}{|c|}{ Aspect Ratio } \\
\hline WF fraction (mesh) & Weight & $\begin{array}{l}\text { Bulk loose } \\
\text { density }\end{array}$ & $\begin{array}{l}\text { Mean length } \\
\text { weighted finer } \\
\text { length }\end{array}$ & Average (Std Dev) & Min & Max \\
\hline Non-milled & $(\%)$ & $\left(\mathrm{g} / \mathrm{cm}^{3}\right)$ & $(\mu \mathrm{m})$ & & & \\
\hline $80-100$ & - & 0.17 & - & $5.17(4.18)$ & 1.33 & 22.80 \\
\hline \multicolumn{7}{|l|}{ Ball Milled } \\
\hline $80-100$ & 0.8 & 0.35 & 110 & $1.70(0.59)$ & 1.02 & 4.33 \\
\hline $100-200$ & 5.2 & 0.30 & 109 & $1.69(0.93)$ & 1.00 & 6.80 \\
\hline $200-300$ & 49.8 & 0.23 & 33 & $1.86(0.95)$ & 1.00 & 7.21 \\
\hline $300-400$ & 22.2 & 0.22 & 29 & $2.21(1.15)$ & 1.00 & 7.50 \\
\hline$<400$ & 19.3 & 0.29 & 25 & $1.91(1.07)$ & 1.01 & 7.81 \\
\hline
\end{tabular}

3 replicates for weight, loose bulk density, and particle analyzer. 100 replicates for aspect ratio. 
The bulk density of the ball-milled 80-100 WF was roughly twice the bulk density of the non-milled WF (Table 2). Ball-milled WF ( $<200 \mathrm{mesh}$ ) bulk density ranged from 0.22 to $0.30 \mathrm{~g} / \mathrm{cm}^{3}$. The loose bulk density of the WF increased due to the ball milling process, which can be attributed to a reduction in fiber size and a decrease in aspect ratio.

WF size and distribution was achieved by light scattering particle size analysis. Length-weighted WF size distributions were obtained (Table 2). Screened fractions 80-100 (ball milled) and 100-200 mesh WF had similar average fiber lengths of 110 and $109 \mu \mathrm{m}$, respectively. The remaining screened fractions 200-300, 300-400, and $<400$ mesh WF all exhibited similar average sizes ranging from 25 to $33 \mu \mathrm{m}$. They also had similar fiber size cumulative distributions as shown in figure 1. A Kolmogorov-Smirnov (K-S) statistical test was conducted on the cumulative frequency distributions (Figure 1) to assess fractionated WF after ball-milling. Results indicate there was no significant difference $(\alpha=0.05)$ in the cumulative density function for the WF fractions 200-300, 300-400, and $<400$ mesh. Therefore, the ensuing analyses collapse the WF size fractions into three statistically distinct populations: $80-100$ mesh, 100-200 mesh, and $<200$ mesh WF.

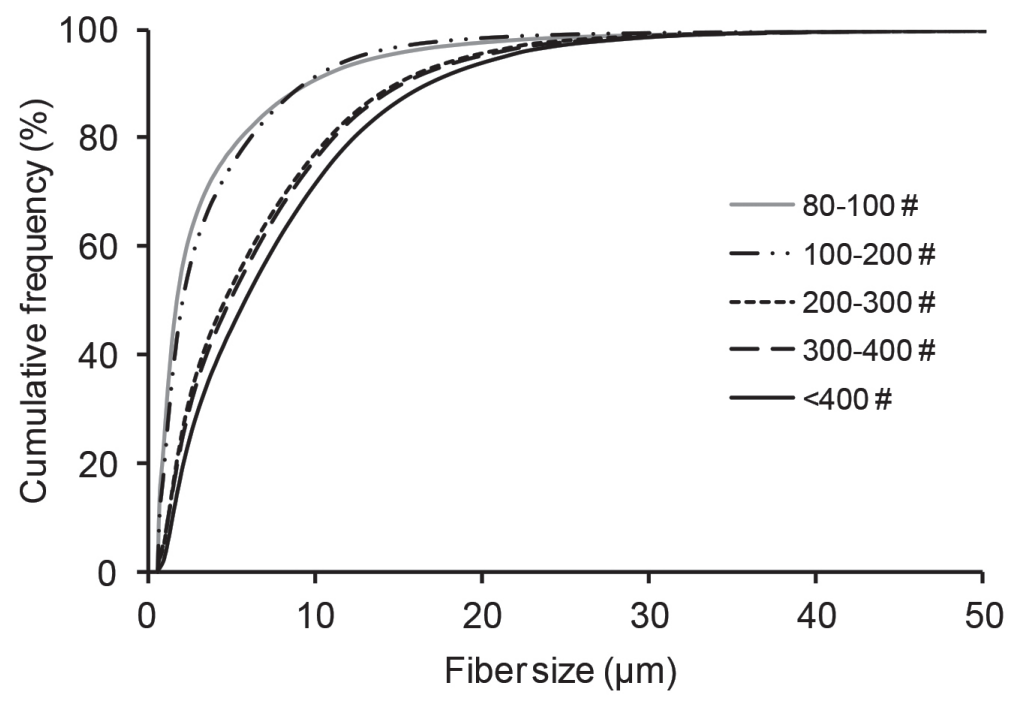

Figure 1. Particle size cumulative frequency distribution of the screened wood fiber fractions.

Optical microscopy was used to measure the aspect ratio of the WF samples (Table 2). The aspect ratio of nonmilled 80-100 mesh WF was 2-3 times higher than the ball-milled WF. The maximum aspect ratio measured for the non-milled WF was 23 compared to a max aspect ratio of 7 for the ball-milled WF. In other words, the non-milled WF was more rod like, and the ball milled WF was more elliptical (Figure 2). These findings may explain why 80-100 ball-milled fibers have a greater bulk density due to better packing than the non-milled WF. 


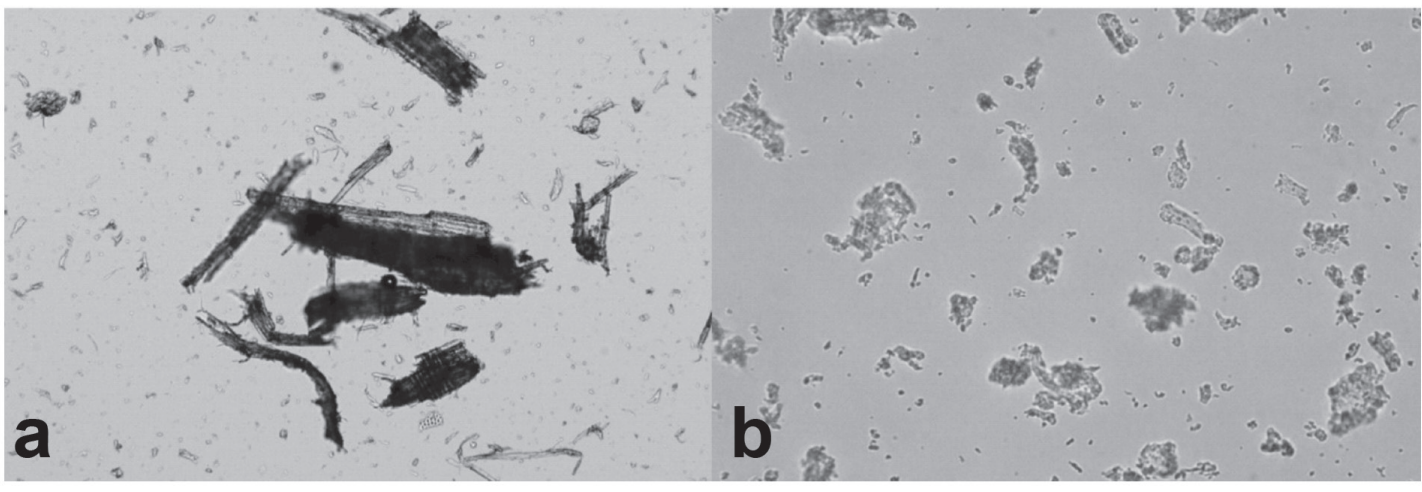

Figure 2. Optical micrographs of wood fibers:

(a) 80-100 mesh fiber fraction and (b) <200 mesh fiber fraction.

\section{Torque Rheometry}

To examine the effect of WF size and content on WPC processing and performance, small batches of screened WF, HDPE and/or MAPE were compounded using a torque rheometer to provide quantitative information on compounding of WPC (Cheng et al. 2001, Yacykewych 2000). Torque rheometry data examined were maximum torque and steady state torque as indicators of WPC compounding. Maximum torque tended to increase as WF content increased (Table 3). An increase in steady state torque, from 31 to $37 \%$, was observed with an increase in wood content from $30 \%$ to $50 \%$. This phenomenon was also observed in talc and calcium carbonate filled polymer systems (da Silva et al. 2002). Results for WPC formulations show that at a particular wood content the maximum torque and the steady state torque recorded decreased with a decrease in WF size (Table 3 and Figure 3). Compounding micron sized WF ( $<200$ mesh) in HDPE reduced the amount of steady state torque by $25 \%$ relative to the coarser WF (80-100 mesh) (Figure 3). Yacykewych (2000) observed similar results for WPC where an increase in WF size (140 to 40 mesh) and content (10 to 40\%) increased dynamic torque measurements.

Table 3. Results from torque rheometry (max and steady state torque) for compounding of WPC formulations.

\begin{tabular}{ccccccc}
\hline $\begin{array}{c}\text { WF size } \\
(\text { mesh })\end{array}$ & $30 \% \mathrm{WF}$ & $40 \% \mathrm{WF}$ & $50 \% \mathrm{WF}$ & $\begin{array}{c}30 \% \mathrm{WF}+ \\
\text { MAPE }\end{array}$ & $\begin{array}{c}40 \% \mathrm{WF}+ \\
\text { MAPE }\end{array}$ & $\begin{array}{c}50 \% \mathrm{WF}+ \\
\text { MAPE }\end{array}$ \\
\hline \multicolumn{7}{c}{ Max torque (Nm) } \\
\hline $80-100$ & 45.7 & 59.3 & 54.4 & 46.6 & 58.4 & 55.4 \\
$100-200$ & 37.7 & 39.3 & 43.9 & 36.6 & 39.6 & 42.4 \\
$<200$ & 40.3 & 42.5 & 41.7 & 37.0 & 37.1 & 42.1 \\
\hline $80-100$ & 11.1 & 12.8 & 15.2 & 11.2 & 13.9 & 17.4 \\
$100-200$ & 9.0 & 10.5 & 11.8 & 10.0 & 11.5 & 14.5 \\
$<200$ & 8.9 & 10.1 & 11.7 & 9.1 & 10.7 & 13.5 \\
\hline
\end{tabular}




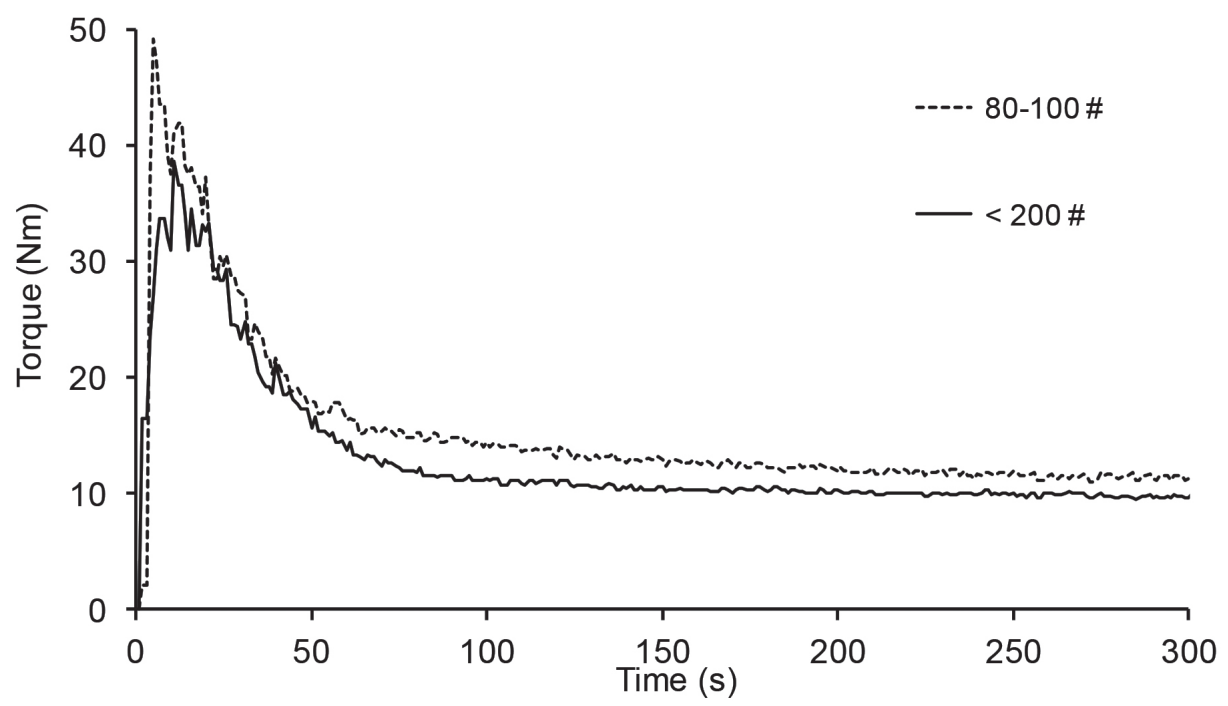

Figure 3. Torque rheometry curves for compounding WPC formulations at $40 \%$ wood loading, showing the effect of wood fiber size (80-100 mesh and $<200$ mesh).

The addition of MAPE coupling agent into the WPC formulation was also investigated and the results are given in Table 3. The amount of torque required at steady state increased within coupled systems compared to uncoupled systems; however, these increases were more significant at higher wood contents. For example, formulations incorporating 80-100 mesh WF increased the steady state torque by $0.9,8.6$, and $14 \%$ at wood contents of 30 , 40 and $50 \%$, respectively, with the addition of MAPE coupling agent compared to uncoupled systems. Li and Wolcott (2005) attributed this increase in resistance to an enhanced interaction between HDPE and wood owing to the presence of MAPE.

\section{Melt Flow Rate}

As a rapid method to examine the flow characteristics of WPC systems in the molten state, MFR and static viscosity were measured for WPC formulations between 10 and 50\% wood contents (Table 4). The MFR of the WPC melt as a function of wood content was shown to decrease as wood content increased (Figure 4). MFR was found to be significantly different between wood contents (Table 4). Specifically, as WF content (80-100 mesh) increased from 30 to $50 \%$ there was an $84 \%$ decrease in MFR. The WPC melt viscosity was shown to increase with an increase in wood loading. The addition of a coupling agent to the WPC formulation significantly decreased the MFR (or increased viscosity) at each individual wood loading compared to uncoupled systems (Figure 4). For example, a decrease in WPC MFR of $11 \%$ was observed at 40\% wood loaded material (80-100 mesh) with the addition of MAPE. However, this significance was not seen in viscosity measurements at $50 \%$ wood loading. This result may be due to increased variability and decreased repeatability at lower MFR. 
Table 4. MFR results for the various WPC formulations. Results with the same letter in their respective column are significantly the same.

\begin{tabular}{ccccccc}
\hline $\begin{array}{c}\text { WF size } \\
(\text { mesh })\end{array}$ & $30 \% \mathrm{WF}$ & $40 \% \mathrm{WF}$ & $50 \% \mathrm{WF}$ & $\begin{array}{c}30 \% \mathrm{WF}+ \\
\text { MAPE }\end{array}$ & $\begin{array}{c}40 \% \mathrm{WF}+ \\
\text { MAPE }\end{array}$ & $\begin{array}{c}50 \% \mathrm{WF}+ \\
\text { MAPE }\end{array}$ \\
\hline \multicolumn{7}{c}{ Average Mass Flow Rate (g/10min) } \\
\hline $80-100$ & 2.50 & 1.22 & 0.41 & $2.37 \mathrm{a}$ & 1.09 & 0.35 \\
$100-200$ & $2.86 \mathrm{a}$ & $1.77 \mathrm{a}$ & 0.67 & $2.41 \mathrm{a}$ & $1.41 \mathrm{a}$ & 0.58 \\
$<200$ & $2.90 \mathrm{a}$ & $1.73 \mathrm{a}$ & 0.79 & 2.58 & $1.43 \mathrm{a}$ & 0.65 \\
\hline $80-100$ & 14700 & 30700 & 90000 & $15600 \mathrm{a}$ & 34000 & 107000 \\
$100-200$ & $12900 \mathrm{a}$ & $20900 \mathrm{a}$ & 55400 & $15300 \mathrm{a}$ & $26200 \mathrm{a}$ & 64100 \\
$<200$ & $12700 \mathrm{a}$ & $21400 \mathrm{a}$ & 46900 & 14300 & $26000 \mathrm{a}$ & 56900 \\
\hline
\end{tabular}

*Melt flow rate values were based on 4 replicates

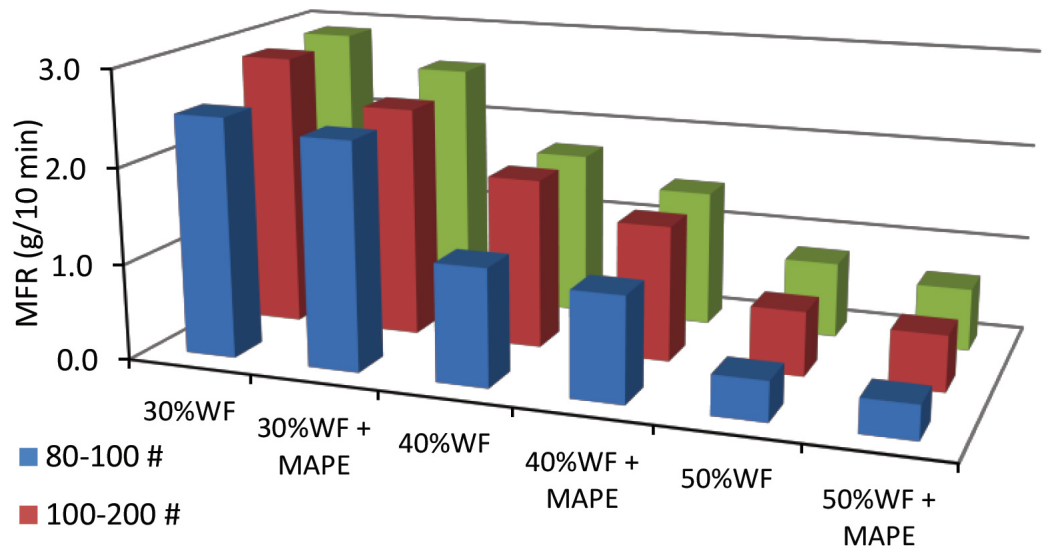

- $<200$ \#

Figure 4. Graph showing the influence of wood content, fiber size and addition of MAPE coupling agent on WPC melt flow rate. 
A decrease in WF size was shown to significantly increase the MFR (decrease in melt viscosity) of the WPC systems. The results suggest that as wood loading increases so does the effect of WF size on MFR and viscosity. At $10 \%$ and $20 \%$ wood loadings there was no significant difference in MFR between WPC of differing WF sizes (data not shown). At 30 and 40\% wood loading, 80-100 mesh's MFR was found to be significantly less than the small WF sizes, 100-200 and <200 mesh. The MFR for the 100-200 and <200 mesh WPC formulations were statistically identical. As discussed earlier, these WF fractions have similar aspect ratios compared to the 80-100 mesh fraction. At $50 \%$ wood loading, MFRs of each WF size were found to be significantly different from one another. This data suggests that WF size plays a larger role at higher wood loadings which could be attributed to packing. For example, it was found that at $30 \%$ wood loading of $<200$ mesh WF $(2.9 \mathrm{~g} / 10 \mathrm{~min})$ had a $16 \%$ greater MFR than $80-100$ mesh WF ( $2.5 \mathrm{~g} / 10 \mathrm{~min})$. At $40 \%$ wood loading, this effect was more pronounced as WPC made with $<200$ mesh WF had a significantly higher MFR (by 41\%) than that of WPC made from coarser WF. The reduction in WF size was most pronounced at 50\% wood loading, where there was an increase in WPC MFR at $<200$ mesh $(0.79 \mathrm{~g} / 10 \mathrm{~min})$, by $93 \%$, relative to $80-100$ mesh WF $(0.41 \mathrm{~g} / 10 \mathrm{~min})$. Similar trends were observed for melt viscosity (i.e., MFR increases while viscosity decreases for a given sample set).

Stark and Berger (1997b) showed and opposite trend in that MFR decreased with an increase in filler content and a decrease in WF size. They attributed this increase in MFR to an increase in unfilled regions in the systems containing larger WF. This trend is acknowledged as a function of the differences in the geometries of the WF (Shenoy 1999, Barnes 2000).

Slightly different results can be seen in MAPE coupled systems compared to uncoupled systems. Wood loading was found to significantly affect MFR and viscosity, as each level of wood loading was significantly different from the others. At 30\% wood loadings within the coupled systems, 80-100 and 100-200 mesh WF performed similarly. At $40 \%$ wood loading, $100-200$ and $<200$ mesh performed similarly. At $50 \%$ wood loading, all WF sizes performed significantly differently from each other.

Multiple regressions were conducted to observe the impact of each variable and variable interactions on MFR and viscosity (Table 5). Wood content (-1.043) was found to be the most influential variable, acting to reduce MFR (or increase viscosity). The second most influential variable was the interaction between WF size and MAPE coupling agent (-0.308), which resulted in a reduction in MFR (or increase viscosity). For example, at 50\% wood loading the addition of coupling agent in the formulation containing 80-100 mesh WF there was a reduction in MFR by $15 \%$, where a reduction of $18 \%$ was seen in formulations containing $<200$ mesh WF.

Table 5. Reported standardized betas and their significance for MFR results.

\begin{tabular}{l|c|c|c|c}
\hline \multicolumn{1}{c|}{ Effects } & \multicolumn{2}{c|}{ Melt Flow Rate } & \multicolumn{2}{c}{ Viscosity } \\
\hline WF size & Beta & Sig. & Beta & Sig. \\
Wood content & -0.015 & 0.573 & 0.137 & 0.119 \\
MAPE & -1.043 & 0.000 & 1.020 & 0.000 \\
WF size*wood content & 0.051 & 0.173 & -0.106 & 0.387 \\
WF size*MAPE & 0.114 & 0.002 & -0.539 & 0.000 \\
MAPE*wood content & -0.308 & 0.000 & -0.527 & 0.002 \\
WF size*MAPE*wood content & 0.277 & 0.000 & 0.272 & 0.073 \\
\hline
\end{tabular}


The MFR results support the torque rheology results. However, these results show that an increase in wood loading increases viscosity or torque required to compound the filled polymer system. The introduction of microsized WF resulted in an ease in processing and decrease in viscosity. Differences were observed between MAPE coupled and uncoupled systems; specifically, coupled systems experienced an increase in viscosity (increased torque measurements) over uncoupled systems.

\section{Mechanical Properties}

The flexural properties (MOR, MOE, and EMFE) were determined on the various WPC formulations (Table 6, Figure 5). Statistical analyses were performed on data from 30 to 50\% WF content and the three classified fibers (comparison of means, specifically Fisher's Least Significant Difference (LSD), and t-tests) (Table 7).

Table 6. Flexural properties of various WPC samples. Values for coefficient of variation are given in parentheses.

\begin{tabular}{lccccccc}
\hline $\begin{array}{c}\text { WF } \\
\text { fraction } \\
\text { (mesh) }\end{array}$ & $30 \% \mathrm{WF}$ & $40 \% \mathrm{WF}$ & $50 \% \mathrm{WF}$ & $\begin{array}{c}\mathrm{WF} \\
\text { fraction } \\
\text { (mesh) }\end{array}$ & $\begin{array}{c}30 \% \mathrm{WF}+ \\
\text { MAPE }\end{array}$ & $\begin{array}{c}40 \% \mathrm{WF}+ \\
\text { MAPE }\end{array}$ & $\begin{array}{c}50 \% \mathrm{WF}+ \\
\text { MAPE }\end{array}$ \\
\hline $80-100$ & $36.0(4.5)$ & $29.7(9.0)$ & $23.9(1.5)$ & $80-100 \mathrm{a}$ & $45.1(1.6)$ & $49.2(6.7)$ & $46.6(5.1)$ \\
$100-200$ & $34.5(6.2)$ & $37.7(3.6)$ & $36.8(2.3)$ & $100-200 \mathrm{a}$ & $38.6(3.7)$ & $46.7(2.3)$ & $54.8(3.8)$ \\
$<200$ & $33.6(3.8)$ & $35.6(3.7)$ & $37.7(6.8)$ & $<200 \mathrm{a}$ & $37.6(3.7)$ & $45.0(4)$ & $53.2(7.6)$ \\
\hline & & MOE (GPa) & & & & MOE (GPa) & \\
\hline $80-100 \mathrm{a}$ & $1.73(3.9)$ & $2.02(8.7)$ & $2.51(5.2)$ & $80-100 \mathrm{a}$ & $1.77(1.6)$ & $2.01(6.8)$ & $2.14(7.7)$ \\
$100-200 \mathrm{ab}$ & $1.46(10)$ & $1.80(5.5)$ & $2.35(3)$ & $100-200 \mathrm{ab}$ & $1.37(5.2)$ & $1.78(2.8)$ & $2.27(3.7)$ \\
$<200 \mathrm{~b}$ & $1.36(7)$ & $1.66(6.9)$ & $2.06(4.8)$ & $<200 \mathrm{~b}$ & $1.30(6.4)$ & $1.65(6.7)$ & $2.13(11)$ \\
\hline & & $\mathrm{EMFE}(\mathrm{J})$ & & & & EMFE (J) & \\
\hline $80-100$ & $0.478(10)$ & $0.216(19)$ & $0.107(15)$ & $80-100 \mathrm{a}$ & $0.577(1.7)$ & $0.629(8.4)$ & $0.383(6.4)$ \\
$100-200 \mathrm{a}$ & $0.446(5.2)$ & $0.472(11)$ & $0.228(12)$ & $100-200 \mathrm{a}$ & $0.488(3.0)$ & $0.609(3.7)$ & $0.582(10)$ \\
$<200 \mathrm{a}$ & $0.436(4.2)$ & $0.469(4.3)$ & $0.394(31)$ & $<200 \mathrm{a}$ & $0.477(3.6)$ & $0.581(4.2)$ & $0.664(9.9)$ \\
\hline
\end{tabular}

Results with the same letter in their respective column are significantly the same. 

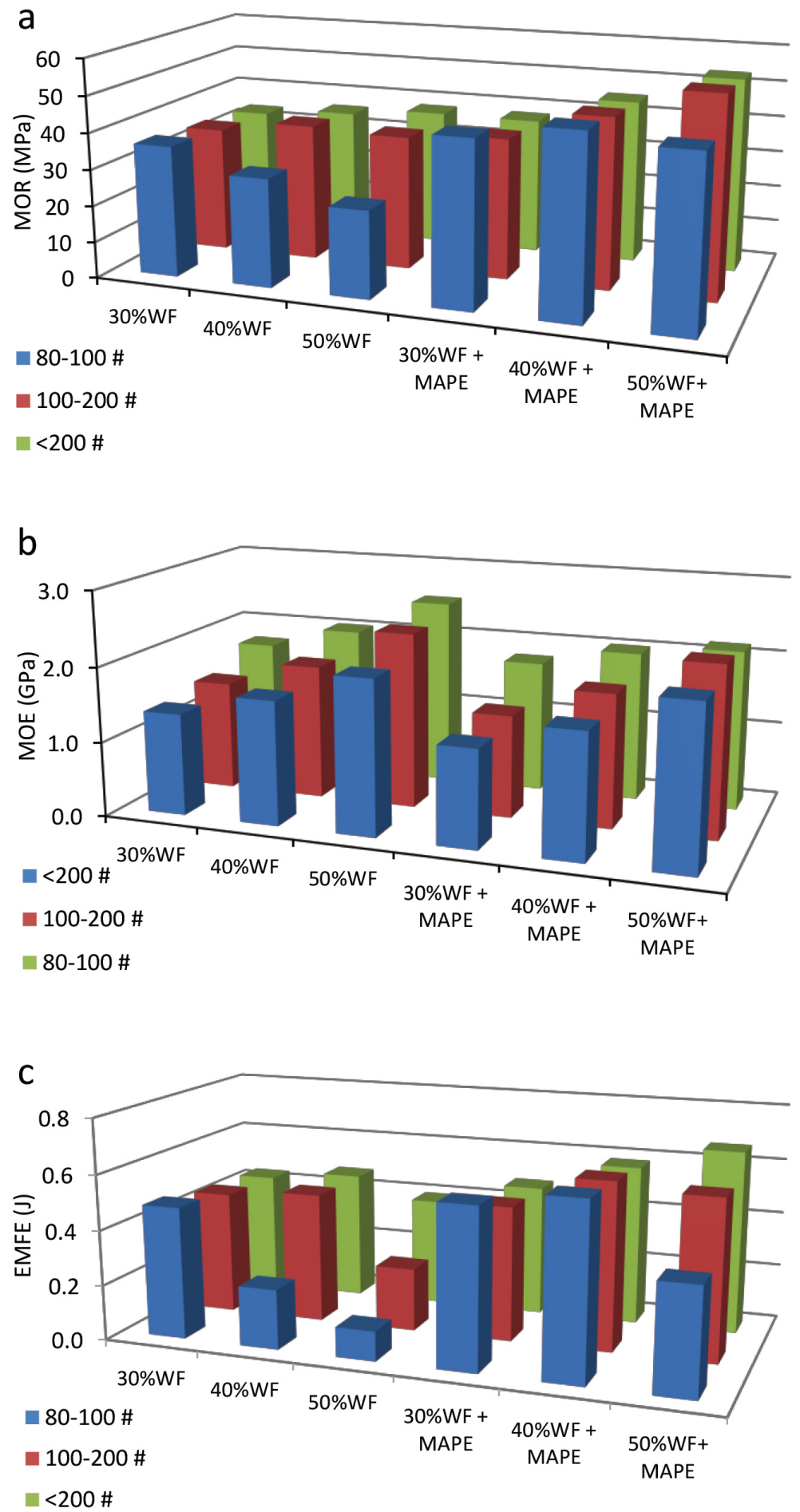

Figure 5. Graph showing the influence of wood content, fiber size and addition of MAPE coupling agent on flexural (a) MOR, (b) MOE, and (c) EMFE. 
For the uncoupled WPC systems ( 30 to 50\% WF) the MOR ranged between 24 and $38 \mathrm{MPa}$ (Figure 5a). A reduction in MOR was present in samples made from 80-100 mesh WF as WF content increased from 30 to $50 \%$. An increase WPC MOR was observed as WF loading increased for the WF size fractions, 100-200 and <200 mesh. WPC made from 80-100 mesh WF at higher wood loading resulted in a significant decrease in MOR relative to those produced from 100-200 and $<200$ mesh WF fractions. Stark and Rowlands (2003) observed a similar trend, where by smaller WF performed significantly better than coarser fibers in MOR. Furthermore, they attributed this trend to larger stress concentrations along the naturally weak interface of the larger WF.

The addition of a coupling agent (2\% MAPE) to the WPC resulted in a significant increase in MOR over the uncoupled systems at all WF loadings and resulted in a maximum strength of $55 \mathrm{MPa}$ (Table 6 and Figure 5a). For example, at $50 \%$ WF loading using $<200$ mesh WF, addition of MAPE in the WPC resulted in a $41 \%$ increase in MOR. This phenomenon was also observed by Stark and Berger (1997b). In terms of wood loading for the 100-200 and $<200$ mesh WPCs, MOR increases as loading increases with the presence of MAPE. Several researchers have also shown similar increases in MOR with the incorporation of coupling agents in WPC formulations (Bledzki and Faruk 2003, English et al. 1996, Stark and Rowlands 2003). MAPE increases the interfacial interaction between the wood fiber and polymer matrix (Rude and Laborie 2008). In terms of WF size, it was found that coupled systems containing 100-200 and $<200$ mesh WF at 50\% content performed better than the larger 80-100 mesh WF. The addition of MAPE results in a larger, more efficient stress transfer between the wood and polymer.

The MOE of the WPC formulations was generally shown to increase with an increase in WF content from 30 to $50 \%$ (Table 6 and Figure 5b). This trend is consistent with that reported in the literature (Bledzki and Faruk 2003). A decrease in WPC MOE was generally observed as the wood fiber size decreased. This trend was also seen by Stark and Rowlands (2003), where MOE significantly decreased with a decrease in WF size below 70 to 235 mesh. It is generally believed that the larger the aspect ratio of fibers results in more stress transfer across the matrix to the fiber (Stark and Rowlands 2003). In this case, the aspect ratio of the largest fiber, 80-100 mesh, may not be large enough to impart additional stress transfer. The addition of MAPE was not significant in improving MOE.

The EMFE of the WPC samples was examined to measure the toughness of WPC formulations (Table 6 and Figure 5c). For the uncoupled 80-100 and 100-200 mesh WPCs it was shown that EMFE decreased with an increase in wood loading. For example, in a highly filled (50\%) WPC, the EMFE decreased from 0.40 to $0.11 \mathrm{~J}$, with an increase in WF size from $<200$ to 80-100 mesh. The EMFE of the WPC made from 80-100 mesh WF was significantly different than WPC made from the other two screened WF fractions. These results suggest that the larger WF (e.g. 80-100 mesh) had a corresponding higher stress concentration along the fiber-polymer interface due to a decrease in surface area. Therefore, with smaller $(<200$ mesh) WF the stress concentrations were smaller due to a larger surface area.

The addition of MAPE to the WPC formulations significantly increased the toughness of the WPC material (Figure 5c). WPC made from $<200$ mesh WF at $50 \%$ loading performed significantly better than WPC samples from 100-200 and 80-100 mesh WF. These findings support the improved fiber-plastic interaction by addition of a coupling agent and, therefore, increased toughness.

Multiple regressions were conducted to observe the impact of each variable (WF size, loading, and MAPE) and variable interactions on flexural properties (Table 7). The standardized betas (given in parentheses) of each independent variable and their interactions are shown, as well as their level of significance. Non-significant variables were left in the models since it was only a hypothesis test. Interaction between wood loading and MAPE was one of the most influential variables within the formulations for WPC flexural properties. For MOR, the interaction between MAPE * wood loading (1.097) was most influential, suggesting that MAPE plays a larger role in increasing MOR at higher wood loadings. The second most influential variable was the interaction between WF size * wood loading (0.544), suggesting that WF size plays a larger role in increasing MOR at higher wood loadings. The third most influential variable was the interaction between WF size * MAPE (-0.481). With respect to MOE, it was found that wood loading (1.129) was the most influential variable. The second most influential variable was the highest order interaction (0.687), which suggests that the combination of high wood loading, reduced particle size, 
and addition of MAPE positively affect MOE. Third, was the interaction between WF size * MAPE (-0.546). For flexural EMFE, the interaction between MAPE * wood loading (1.094) was the most influential variable, suggesting that MAPE plays a larger role in increasing flexural EMFE at higher wood loadings. The second most influential variable was WF size * wood loading $(0.931)$. The third most influential variable was wood loading $(-0.788)$ which had a negative effect on EMFE.

Table 7. Shows the result of multiple regression of the mechanical test results.

\begin{tabular}{lcccccc}
\hline Effects & \multicolumn{2}{c}{ Flexural strength } & \multicolumn{2}{c}{ Flexural modulus } & \multicolumn{2}{c}{ Flexural EMFE } \\
& Beta & Sig. & Beta & Sig. & Beta & Sig. \\
\hline WF size & -0.154 & 0.008 & -0.069 & 0.145 & -0.215 & 0.027 \\
Wood loading & -0.164 & 0.008 & $\underline{\mathbf{1 . 1 2 9}}$ & $\underline{\mathbf{0 . 0 0 0}}$ & $\mathbf{- 0 . 7 8 8}$ & $\mathbf{0 . 0 0 0}$ \\
MAPE & -0.024 & 0.766 & 0.077 & 0.246 & -0.047 & 0.726 \\
WF size*wood loading & $\mathbf{0 . 5 4 4}$ & $\mathbf{0 . 0 0 0}$ & -0.328 & 0.000 & $\mathbf{0 . 9 3 1}$ & $\mathbf{0 . 0 0 0}$ \\
WF size*MAPE & $\mathbf{- 0 . 4 8 1}$ & $\mathbf{0 . 0 0 0}$ & $-\mathbf{0 . 5 4 6}$ & $\mathbf{0 . 0 0 0}$ & -0.318 & 0.090 \\
MAPE* wood loading & $\underline{\mathbf{1 . 0 9 7}}$ & $\underline{\mathbf{0 . 0 0 0}}$ & -0.235 & 0.004 & $\underline{\mathbf{1 . 0 9 4}}$ & $\underline{\mathbf{0 . 0 0 0}}$ \\
WF size*MAPE*Wood loading & 0.102 & 0.424 & $\mathbf{0 . 6 8 7}$ & $\mathbf{0 . 0 0 0}$ & -0.051 & 0.812
\end{tabular}

Standardized betas are shown, as well as their significance. The table is coded to show the most influential betas (largest effect underlined bold, medium effect bold, and minimal effect italized bold).

\section{Thermal Analysis}

DSC was employed to investigate the extent of HDPE crystallization within the various WPC formulations (Table 8 and Figure 6). The melting enthalpy (from the $2^{\text {nd }}$ melt) was used to determine the extent of crystallization in HDPE (Wunderlich 1973). The extent of crystallization of HDPE in 100-200 and <200 mesh WPC was shown to decrease as the WF content increased. It is postulated that at 30\% WF loading, HDPE nucleation at the fiber surface has room to form spherulites (Harper and Wolcott 2004), but at higher wood loadings, nucleation may be impeded by the close proximity of neighboring fibers, due to the increased packing density. In formulations containing 80-100 mesh, with low packing density, there is potential space between neighboring fibers to allow spherelites to form into highly structured networks. This reduction in HDPE crystallinity observed with the introduction of micro-sized WF can help explain the reduction in flexural modulus. With a decrease in crystallinity comes a decrease in stiffness allowing the MOE of the WPC to decrease, while improving the toughness of these WPC systems. The addition of MAPE coupling agent to the WPCs did not show any difference in the extent of HDPE crystallinity in formulations containing 100-200 and $<200$ mesh WF. However, it appears that MAPE actually impeded crystallization within formulation containing 80-100 mesh WF at 30 and 40\% loading, but aided crystallization at 50\% loading by increasing HDPE crystallinity to $41 \%$. 
Table 8. DSC analysis results showing the effect that WF loading, WF size, and addition of MAPE on crystallization temperature and crystallinity of HDPE in the WPC formulations.

\begin{tabular}{|c|c|c|c|c|c|c|}
\hline \multirow[t]{2}{*}{ WF size (mesh) } & \multicolumn{2}{|c|}{$30 \% \mathrm{WF}$} & \multicolumn{2}{|c|}{$40 \% \mathrm{WF}$} & \multicolumn{2}{|c|}{$50 \% \mathrm{WF}$} \\
\hline & $\mathrm{T}_{\mathrm{C}}\left({ }^{\circ} \mathrm{C}\right)$ & \% Cryst & $\mathrm{T}_{\mathrm{C}}\left({ }^{\circ} \mathrm{C}\right)$ & $\%$ Cryst & $\mathrm{T}_{\mathrm{C}}\left({ }^{\circ} \mathrm{C}\right)$ & \% Cryst \\
\hline \multicolumn{7}{|l|}{ Uncoupled WPC } \\
\hline HDPE & 115.0 & 34 & & & & \\
\hline $80-100$ & 117.5 & 37 & 116.5 & 35 & 116.4 & 36 \\
\hline $100-200$ & 117.9 & 38 & 117.3 & 32 & 116.4 & 30 \\
\hline$<200$ & 118.0 & 38 & 117.0 & 34 & 116.9 & 34 \\
\hline \multicolumn{7}{|l|}{ MAPE coupled } \\
\hline $80-100$ & 116.6 & 26 & 116.0 & 30 & 117.5 & 41 \\
\hline $100-200$ & 118.6 & 43 & 117.5 & 31 & 117.5 & 36 \\
\hline$<200$ & 118.4 & 39 & 118.0 & 33 & 117.4 & 35 \\
\hline
\end{tabular}

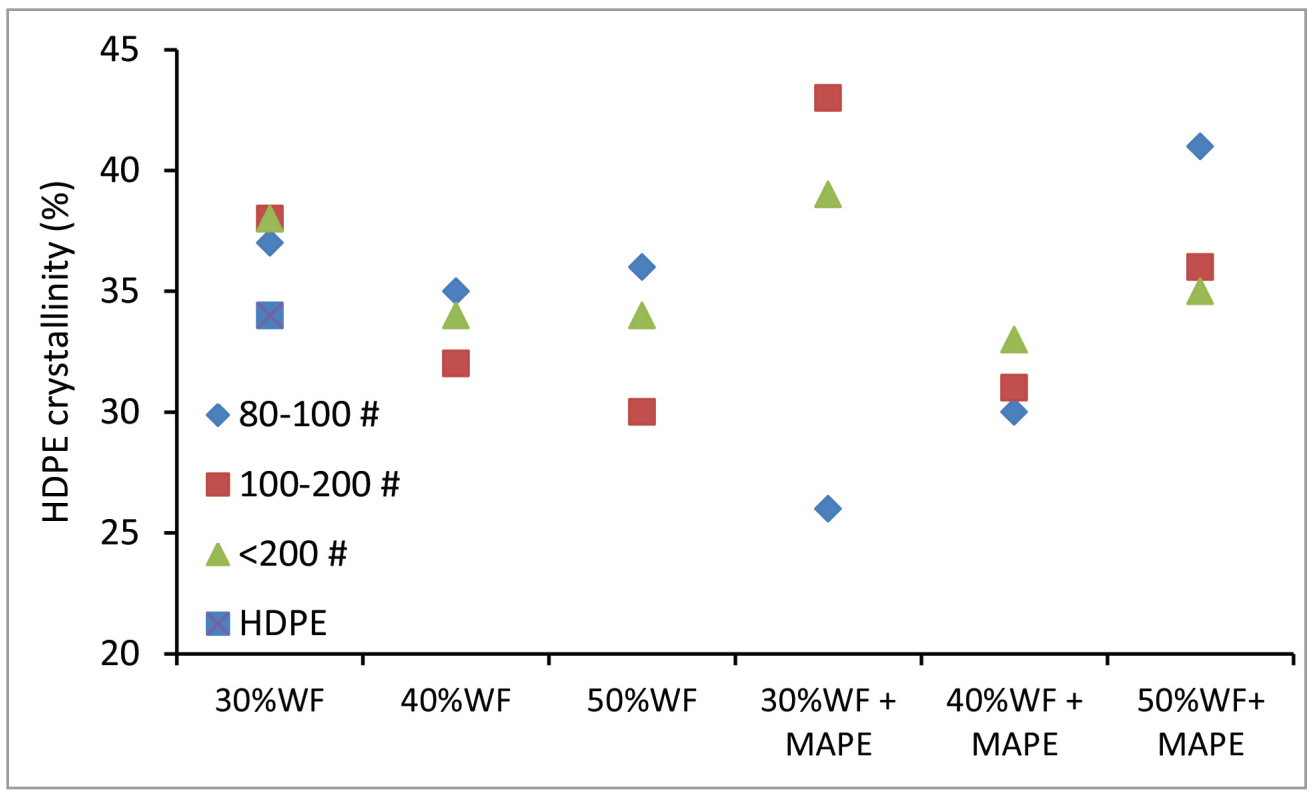

Figure 6. Graph showing the influence of wood content, fiber size and addition of MAPE coupling agent on WPC HDPE crystallinity. 
The crystallization temperature $\left(\mathrm{T}_{\mathrm{c}}\right)$ of $\operatorname{HDPE}\left(1150^{\circ} \mathrm{C}\right)$ in the WPC was measured as a test of the kinetic component of HDPE crystallization (Table 8). HDPE's $\mathrm{T}_{c}$ was shown to increase to $118.4^{\circ} \mathrm{C}$ with the incorporation of micron sized nucleating WF ( $<200 \mathrm{mesh})$ at $30 \%$ wood loading. These data suggest that the crystallization mechanism of HDPE was induced at a slightly higher temperature by incorporation of micron sized WF (which promote nucleation). Thus, the smaller WF has a bearing on the mechanical properties of the WPC (Tang et al. 2004). The addition of MAPE coupling agent raised the $T_{c}$ for the WPC systems as compared to the uncoupled WPC systems. For example, the $T_{c}$ increased slightly from 116.4 to $117.5^{\circ} \mathrm{C}$ upon addition of MAPE (80-100 mesh, $50 \%$ wood content). The addition of a coupling agent to WPC seems to have played a larger role in HDPE crystallization than WF size.

\section{CONCLUSIONS}

Micro-sized WF can be generated by ball-milling and screened into discrete fractions and used in WPC. The WF geometries and size were shown to have an effect on WPC rheological properties. The use of micro-size WFs results in improved compoundability and decreased melt viscosity. The addition of micron sized WF to the WPC formulation increased toughness. This is possibly due to the mechanism in which a lower stress concentration between the wood fiber and matrix is a result of the large surface area. The impact of these findings include (i) higher wood loading can be used in WPC preparation by incorporating smaller wood fibers, (ii) higher wood loading can be used in low viscosity resin applications (with no reduction in WPC properties) such as injection molding, and (iii) higher wood loading can increase production rates. However, with an increase in wood loading comes an increase in biological degradation. Therefore, possible applications could be for indoor use in molding and millwork.

\section{ACKNOWLEDGEMENTS}

This research was supported by the National Research Initiative of the USDA CSREES, grant number 200335103-12902. The DSC hot-stage was supported by a USDA-CSREES grant number 2003-35503-13697. The authors would like to acknowledge the technical assistance of Drs. M.P. Wolcott and K. Englund at Washington State University and statistical analysis by Dr. Steven Shook at the University of Idaho. 


\section{REFERENCES}

ASTM International. 2008. Standard test method for flexural properties of unreinforced and reinforced plastics and electrical insulating materials. ASTM D 790-07. West Conshohocken, PA.

ASTM International. 2008. Standard test method for melt flow rates of thermoplastics by extrusion plastometer. ASTM D1238-01e1. West Conshohocken, PA.

Barnes, A.H. 2000. A Handbook of Elementary Rheology. University of Wales Institute of Non-Newtonian Fluid Mechanics, Aberystwyth, Wales.

Bledzki, A.K.; Faruk, O. 2003. Wood fibre reinforced polypropylene composites: Effect of fibre geometry and coupling agent on physico-mechanical properties. Applied Composite Materials 10: 365-379.

Cheng, B.; Zhou, C.; Yu, W.; Sun, X. 2001. Evaluation of rheological parameters of polymer melts in torque rheometers. Polymer Testing 20: 811-818.

Clemons, C. 2002. Wood-plastic composites in the United States: The Interfacing of two industries. Forest Products Journal 52 (6): 10-18.

da Silva, A.L.N.; Rocha, M.C.G.; Moraes, M.A.R.; Valente, C.A.R.; Coutinho, F.M.B. 2002. Mechanical and rheological properties of composites based on polyolefin and mineral additives. Polymer Testing 2: 57-60.

Dae Han, C. 1974. Rheological properties of calcium carbonate-filled polypropylene melts. Journal of Applied Polymer Science 18: 821-829.

Dalsgaard, K.; Jensen, J.L.; Sorensen, M. 1991. Methodology of sieving small samples and calibration of sieve set. In J.P.M. Syvitski, eds. Principles, methods, and application of particle size analysis. Cambridge University Press, New York, pp. 64-75.

Dong, S.; Sapieha, S.; Schreiber, H.P. 1992. Rheological properties of corona modified cellulose/polyethylene composites. Polymer Engineering and Science 32 (22): 1734-1739.

English, B.; Clemons, C.M.; Stark, N.; Schneider, J.P. 1996. Waste-wood-derived fillers for plastics. USDAForest Service-Forest Products Laboratory General Technical Report FPL-GTR-91.

Fabiyi, J.S.; McDonald, A.G.; Wolcott, M.P.; Griffith, P.R. 2008. Wood plastic composites weathering: Visual appearance and chemical change. Polymer Degradation and Stability 93: 1405-1414.

Fabiyi, J.S.; McDonald, A.G. 2010. Effect of wood species on property and weathering performance of wood plastic composites. Composites Part A 41:1434-1440.

Fabiyi, J.S.; McDonald, A.G.; Morrell, J.J.; Freitag, C. 2011. Structural characterization of wood species on biodegradation of wood plastic composites. Composites part A 42: 501-510.

George, J.; Janardhan, R.; Anand, J.S.; Bhagawan, S.S.; Thomas, S. 1996. Melt rheological behavior of short pineapple fibre reinforced low density polyethylene composites. Polymer 37 (24): 5421-5431.

Guo, R.; Azaiez, J.; Bellehumeur, C. 2005. Rheology of fiber filled polymer melts: Role of fiber-fiber interactions and polymer-fiber coupling. Polymer Engineering and Science 45 (3): 385-399. 
Harper, D.; Wolcott, M. 2004. Interaction between coupling agent and lubricants in wood-polypropylene composites. Composites: Part A 35: 385-394.

LeBaron, P.C.; Wang, Z.; Pinnavaia, T.J. 1999. Polymer-layered silicate nanocomposites: an overview. Applied Clay Science 15: 11-29.

Lee, B.; McDonald, A.G.; James, B. 2001. Influence of fiber length on the mechanical properties of woodfiber/polypropylene prepreg sheets. Materials Research Innovations 4: 97-103.

Liew, K.C.; Harum, J.; Tahir, P.M.; Yusoff, M.N.M.; Dahlan, K.Z.M. 2000. Properties of rubberwood fibre-polypropylene composites blended at different fibre contents and fibre size fractions. Journal of Tropical Forest Products 6 (1): 21-27.

Li, T.Q.; Wolcott, M.P. 2004. Rheology of HDPE-wood composites. I. Steady state shear and extensional flow. Composites Part A 35: 303-311.

Li, T.Q.; Wolcott, M.P. 2005. Rheology of wood plastics melt. Part 1. Capillary rheometry of HDPE filled with maple. Polymer Engineering and Science 45 (4): 549-559.

Lim Y.T.; Park, O.O. 2001. Phase morphology and rheological behavior of polymer/layered silicate nanocomposites. Rheologica Acta 40: 220-229.

Maiti, S.N.; Hassan, M.R. 1989. Melt rheological properties of polypropylene-wood flour composites. Journal of Applied Polymer Science 37: 2019-2032.

Marcovich, N.E.; Reboredo, M.M.; Kenny, J.; Aranguren, M.I. 2004. Rheology of particle suspensions in viscoelastic media: Wood flour polypropylene melt. Rheologica Acta 43: 293-303.

McDonald, A.G.; Donaldson, L.A.; Singh, A.P.; Alexander, J.; Murton, K.D. 1997. Characterisation of radiata pine HTMP fibres by electron, UV, and confocal scanning laser microscopy. In Hague J, Loxton C, Bolton, J, Mott L (eds) Proc. 1st European Panel Products Symp. Llandudno, Wales. p 41

Morrell, J.J.; Stark, N.M.; Pendleton, D.E.; McDonald, A.G. 2006. Durability of wood-plastic composites. Wood Design Focus 16 (3): 7-10.

Rude, E.; Laborie, M-P. 2008. 13C CP/MAS NMR investigation of the interactions between maleic anhydride polypropylene and wood polymers. Applied Spectroscopy 62 (5): 562-568.

Shenoy, A.V. 1999. Rheology of filled polymer systems. Kluwer Academic Publishers. Norwell, MA, USA.

Stark, N.M.; Berger, M.J. 1997a. Effect of particle size on properties of wood-fiber reinforced polypropylene composites. In Proc. Woodfiber-Plastic Composites Conference, Forest Products Society, Madison, Wisconsin, USA, May 12-14, pp. 134-143.

Stark, N.M.; Berger, M.J. 1997b. Effect of species and particle size on properties of wood flour filled polypropylene composites. In Proc. Functional Fillers for Thermoplastics and Thermosets, Interteck Conferences, SanDiego, CA. December 8-10, pp. 1-16.

Stark, N.M.; Rowlands, R.E. 2003. Effects of wood fiber characteristics on mechanical properties of wood/ polypropylene composites. Wood and Fiber Science 35 (2): 167-174. 
Tang, J.; Wang, Y.; Liu, H.; and Belfiore, L.A. 2004. Effects of organic nucleating agents and zinc oxide nanoparticles on isotactic polypropylene crystallization. Polymer 45(7): 2081- 2091.

Wunderlich, B. 1973. Macromolecular physics: crystal structure, morphology, defects. vol. 1. Academic Press, New York, NY. pp. 388-389.

Yacykewych, A. 2000. Evaluation of a wood fiber-based compound by torque rheometry. ANTEC-Society of Plastic Engineers. pp. 2193-2197

Zaini, M.J.; Fuad, M.Y.; Ismail, Z.; Mansor, M.S.; Mustafah, J. 1996. The effect of filler content and size on the mechanical properties of polypropylene/oil palm wood flour composites. Polymer International 40: 51-55. 